\title{
Characteristics and Incidence of Inpatient Ophthalmology Consultations to Screen for Papilledema
}

\author{
Peter J. Belin, MD ${ }^{1}$ Giovanni H. Greaves, $\mathrm{MD}^{1} \quad$ Jules Winokur, MD ${ }^{1}$ Matthew Gorski, MD ${ }^{1}$ \\ ${ }^{1}$ Department of Ophthalmology, Donald and Barbara Zucker School \\ of Medicine at Hofstra/Northwell, Hofstra University, Hempstead, \\ Address for correspondence Peter J. Belin, MD, 600 Northern Blvd., \\ New York \\ Suite 214, Hempstead, NY (e-mail: petebelin@gmail.com). \\ J Acad Ophthalmol 2019;11:e40-e43.
}

\begin{abstract}
Objective A frequent reason for ophthalmology consultation is to rule out papilledema. The purpose of this study is to evaluate the incidence of consultations to screen for papilledema in an acute inpatient setting and determine the frequency and factors associated with a positive diagnosis of bilateral optic nerve swelling.

Methods A retrospective chart review was performed of consecutive adult and pediatric inpatient ophthalmology consultations at a tertiary hospital system to "rule out papilledema" from September through November 2016. All patients had a detailed neuro-ophthalmology examination including a dilated fundus exam.

Results A total of 36 consults-13 males and 23 females-with a mean age of 19.8 (range: 3-71) years were called to screen for papilledema. The most common service to request the consult was pediatrics $(44 \%)$, followed by neurosurgery $(42 \%)$, medicine $(8 \%)$, and neurology (6\%). The most frequent reason for consultation was headache (61\%), followed by visual changes (30.5\%) and nausea/vomiting (25\%). A positive diagnosis of bilateral optic nerve swelling occurred in $14 \%$ (5/36) of consults. Of these five consults, four of them were sent into the hospital by an ophthalmologist who noted the bilateral optic nerve swelling and one was noted by an emergency room

Keywords

- papilledema

- optic nerve edema

- ophthalmology consultations

- screening pediatrician.

Conclusion No new cases of bilateral optic nerve swelling were found in screening consults to "rule out papilledema." All of the positive diagnoses in our study had been previously identified by another physician and known to the primary team prior to ophthalmology consultation. Screening consultations for optic nerve swelling may not be an effective way to rule out papilledema.
\end{abstract}

Papilledema refers to optic disc edema due to elevated intracranial pressure (ICP) and was first described in $1853 .^{1}$ The proposed pathogenesis is that elevated ICP causes elevated pressure on the optic nerve, which decreases axoplasmic flow, leading to congestion and edema in the optic nerve head. It is thought that this typically takes 1 to 5 days to develop but depends on the rate of elevation in pressure. ${ }^{2}$ Early papille-

received

June 27, 2019

accepted after revision

October 16, 2019
DOI https://doi.org/

$10.1055 / \mathrm{s}-0039-3400546$ ISSN 2475-4757. dema can present without any symptoms, although it may be associated with symptoms common of increased ICP including headaches which are worse in the morning, nausea and vomiting, pulsatile tinnitus, transient visual obscuration, and/or sixth nerve palsy. Long-standing papilledema can result in visual field defects and loss of vision. The possibility for serious underlying conditions as a cause of papilledema such
Copyright $\odot 2019$ by Thieme Medical Publishers, Inc., 333 Seventh Avenue, New York, NY 10001, USA. Tel: +1(212) 584-4662.
License terms

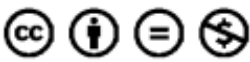


as central nervous system (CNS) tumors or CNS inflammation makes it an ominous finding on fundus examination. When patients are suspected to have elevated ICP, ophthalmologists are often consulted to examine patients to identify papilledema which can help rule-in that possibility.

Ophthalmology consultation is common in both the emergency room and inpatient setting. ${ }^{3}$ One frequent reason for consultation is to rule out papilledema in cases of headache, head trauma, suspected intracranial mass, or prior to lumbar puncture and has been estimated to account for $3.3 \%$ of ophthalmology consults. ${ }^{4}$

Nonetheless, the actual diagnosis of papilledema in such consults is rare. In a study of consultations to rule out papilledema in a pediatric emergency room, papilledema was diagnosed in only 1.2 to $6 \%$ of all consultations., ${ }^{5,6}$ The only clinical factor significantly associated with a positive diagnosis of papilledema was visual complaints associated with headache.

Additionally, the appropriate timing of such consultations has not been well established. It is known that papilledema is typically not present in cases of acute rise in ICP ( $<7$ days), and its absence does not eliminate the possibility of elevated ICP. ${ }^{7}$ In 479 emergency room consults to rule out papilledema, SegevBecker et al found that $60 \%$ of the patients had been symptomatic for $<24$ hours, of which all had normal eye exams. ${ }^{5}$

To date there have been no studies evaluating the clinical factors predictive of making the diagnosis of papilledema in a population of children and adults. The purpose of this study is to evaluate the incidence of ophthalmology consultations to screen for papilledema in an acute inpatient and emergency room setting and determine the frequency and factors associated with a positive diagnosis of bilateral optic nerve swelling.

\section{Methods}

This retrospective case series was approved by the Northwell Health Institutional Review Board. Medical records were reviewed for all consecutive patients who had a hospital-based ophthalmology consult requested for suspected optic disc swelling between September 1, 2016 and December 31, 2016. Consults conducted in the emergency room and inpatient units at North Shore University Hospital, Long Island Jewish Medical Center, and Cohen Children's Medical Center for both adults and children were included in this study. All patients underwent a complete ophthalmologic exam. Examinations included assessment of visual acuity, color vision, pupils, confrontation visual fields, intraocular pressure, extraocular motility, anterior segment, and dilated fundus. Demographics, reason for consult, requesting service, medical and ocular history, associated symptoms, and final diagnosis were recorded.

Evaluation of the optic nerve and diagnosis of optic disc swelling was made based on either direct ophthalmoscopy, indirect ophthalmoscopy, and/or slit lamp biomicroscopy at the patient's bedside or in the hospital eye examination room if the patient's medical and physical condition allowed. The examination was performed by the ophthalmology residents on the consult service and all diagnoses were confirmed by an attending comprehensive ophthalmology hospitalist.
Table 1 Demographics and characteristics of consults

\begin{tabular}{|l|l|}
\hline & Number \\
\hline Total & 36 \\
\hline Average age & 19.8 y (range: 3-71) \\
\hline Gender & $13 / 36(36 \%)$ male \\
\hline Consult requested by: & \\
\hline Pediatrics & $16(44 \%)$ \\
\hline Medicine & $3(8 \%)$ \\
\hline Neurosurgery & $15(42 \%)$ \\
\hline Neurology & $2(6 \%)$ \\
\hline Presenting symptoms: & \\
\hline Visual changes & $11(30.5 \%)$ \\
\hline Headache & $22(61.1 \%)$ \\
\hline Nausea or vomiting & $9(25 \%)$ \\
\hline Bilateral optic nerve swelling & $5(14 \%)$ \\
\hline Referred by outside ophthalmology & $4(11 \%)$ \\
\hline
\end{tabular}

\section{Results}

A total of 36 consults-13 males and 23 females-with a mean age of 19.8 (range: 3-71) years were called to screen for papilledema. The most common service to request the consult was pediatrics ( $44 \%$ ), followed by neurosurgery ( $42 \%)$, medicine $(8 \%)$, and neurology $(6 \%)$. The most frequent reason for consultation was headache (61\%), followed by visual changes (30.5\%) and nausea/vomiting (25\%) (-Table 1).

A positive diagnosis of bilateral optic nerve swelling

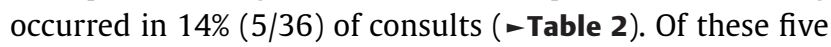
consults, four of them were sent into the hospital by an outpatient ophthalmologist who noted the bilateral optic nerve swelling and one was noted by an emergency room pediatrician. Two out of the five patients with papilledema (40\%) presented with changes in vision, two (40\%) with headache, one (20\%) had nausea and vomiting, one (20\%) had pulsatile tinnitus, and one patient was asymptomatic.

All of the patients with papilledema except one had corrected near-visual acuity of 20/30 or better and none had an afferent papillary defect. Color vision was full in three of the patients, not available in two patients.

The final diagnoses in the patients with papilledema included two with intracranial masses (one pineal germinoma and one atypical meningioma), one with viral meningitis, one with idiopathic intracranial hypertension, and one case of elevated ICP secondary to craniosynostosis.

\section{Discussion and Conclusion}

Ophthalmologists are commonly consulted when there is a concern for elevated ICP to "rule out papilledema," which is potentially vision threatening and more importantly carries the possibility of a life-threatening etiology. Papilledema can develop anywhere from hours to weeks after a rise in ICP. ${ }^{8}$ In our study, 36 consults were called during a 4-month period. 
Table 2 Characteristics of patients with bilateral optic nerve swelling

\begin{tabular}{|l|l|l|l|l|l|l|l|}
\hline Case & $\begin{array}{l}\text { Age } \\
(\mathrm{y}), \mathrm{Sex}\end{array}$ & Symptoms & $\begin{array}{l}\text { Ophthalmology } \\
\text { referred }\end{array}$ & Visual acuity & $\begin{array}{l}\text { Color } \\
\text { (Ishihara) }\end{array}$ & APD & Final diagnosis \\
\hline 1 & $13, \mathrm{~F}$ & $\begin{array}{l}\text { Dilated pupil, restricted } \\
\text { extraocular motility }\end{array}$ & No & $20 / 20 \mathrm{OU}$ & $12 / 12 \mathrm{OU}$ & No & Pineal germinoma \\
\hline 2 & $13, \mathrm{~F}$ & $\begin{array}{l}\text { Headache, nausea, } \\
\text { vomiting }\end{array}$ & Yes & $20 / 20 \mathrm{OU}$ & $12 / 12 \mathrm{OU}$ & No & Viral meningitis \\
\hline 3 & $28, \mathrm{~F}$ & Headache, blurry vision & Yes & $\begin{array}{l}20 / 400 \mathrm{OD}, \\
20 / 20 \mathrm{OS}\end{array}$ & $\mathrm{N} / \mathrm{A}^{\mathrm{a}}$ & $\mathrm{N} / \mathrm{A}^{\mathrm{a}}$ & Atypical meningioma \\
\hline 4 & $10, \mathrm{M}$ & $\begin{array}{l}\text { Craniosynostosis } \\
\text { screening exam }\end{array}$ & Yes & $20 / 30 \mathrm{OU}$ & $\mathrm{N} / \mathrm{A}^{\mathrm{a}}$ & No & $\begin{array}{l}\text { Elevated intracranial } \\
\text { pressure }\end{array}$ \\
\hline 5 & $25, \mathrm{~F}$ & Blurry vision, tinnitus & Yes & $20 / 20 \mathrm{OU}$ & $12 / 12 \mathrm{OU}$ & No & $\begin{array}{l}\text { Idiopathic intracranial } \\
\text { hypertension }\end{array}$ \\
\hline
\end{tabular}

Abbreviations: APD, afferent pupillary defect; F, female; M, male.

a Not able to be performed.

The consulting ophthalmologist made no new diagnoses of papilledema, but confirmed five cases that were previously known to the consulting service.

A common cause of elevated ICP in children is ventriculoperitoneal (VP) shunt failure in patients with a history of hydrocephalus. The overall prevalence of papilledema in cases of VP shunt failure was found to be $14 \%$, and $24 \%$ in those with documented ICP $>200 \mathrm{~mm} \mathrm{H}_{2} \mathrm{O} .{ }^{9}$ Another study found the sensitivity of papilledema in predicting elevated ICP in cases of VP shunt failure to be $23 \%{ }^{5}$ While there have been isolated case reports of VP shunt failure where papilledema was the only presenting sign, it must be noted that this is the exception to the rule. ${ }^{10,11}$ It has also been shown that younger children are less likely to present with papilledema in the setting of elevated ICP. ${ }^{12}$

One limitation of our study was that the duration of symptoms was inconsistently reported and unable to be evaluated. Numerous studies have documented that ICP must be elevated for a sufficient duration to be transmitted to the optic nerve and manifest as papilledema. ${ }^{7,13-15}$ Steffen et al studied 37 patients with acute elevations in ICP who had daily fundus examinations for 7 days after the acute elevation and found that only one patient developed papilledema within 7 days. ${ }^{7}$ The absence of papilledema in the acute setting of raised ICP has also been demonstrated in patients with acute intracranial hemorrhage. ${ }^{15}$ Thus, evaluation for papilledema may be unreliable in the setting of acute onset of symptoms or sudden rise in ICP.

In our study two out of five patients with papilledema were ultimately diagnosed with a CNS mass. Fear of missing an intracranial tumor is the driving force for many consults; however, it appears that papilledema at time of CNS tumor diagnosis is relatively uncommon, being found in $13 \%$ of patients in a meta-analysis of 4,000 pediatric tumors. ${ }^{16}$ Furthermore, a large retrospective review found that the vast majority (96.5\% of 479 patients) of pediatric patients with headaches had normal ophthalmological exams with no evidence of optic disc swelling. ${ }^{5}$

The most common presenting symptom in patients suspected of having papilledema in our study was headache (61\%). Yet, only two of the five patients with papilledema reported headaches. In children evaluated for headache the most common causes are usually extracranial, including upper respiratory infections, sinusitis, migraine, or other infections. Headaches in the absence of other neurologic symptoms are rarely related to serious intracranial causes. ${ }^{17,18}$

Not to be excluded in the assessment of the utility of ophthalmology consults is the cost-both the financial cost as well as the allocation of limited resources-in addition to the time it takes to get and complete an ophthalmology consult. Furthermore, an eye exam can be difficult and upsetting to a child. In addition, not all hospitals have ophthalmologists on staff, which could require a costly and time-consuming transfer to another institution. With the rise of telemedicine, recent studies have assessed the quality of optic nerve photography for diagnostics purposes. In a recent study of 103 children aged 5 to 12 years old, a nonmydriatic digital fundus camera was used to produce clinically satisfactory images with an average reviewer rating 4.6 out of 5 ( $1=$ unsatisfactory and $5=$ satisfactory). Additionally, the average length of time to obtain the image was 1.8 minutes and the average patient cooperation was rated as 4.4 out of 5 ( $1=$ uncooperative, no images obtained and $5=$ very cooperative). ${ }^{19}$ Cost, patient satisfaction, and length of stay could all potentially be improved by utilization of such devices.

In conclusion, no new cases of bilateral optic nerve swelling were found in screening consults to "rule out papilledema" in our study. All of the positive diagnoses in our study had been previously identified by another physician and known to the primary team prior to ophthalmology consultation. There were no significant associations of subjective complaints or objective findings in patients with optic nerve swelling. A review of the literature suggests that dilated fundus examinations may not be a good screening tool to "rule out" elevated ICP, especially in the acute setting. A negative examination for optic nerve swelling does not definitively exclude elevated ICP. Further larger studies must assess the cost effectiveness and utility of screening inpatient eye exams for papilledema.

Funding

None. 


\section{Conflict of Interest}

None declared.

\section{References}

1 Türck L. Ein Fall von Hämorrhagie der Netzhaut beider Augen. Druck von C. Gerold \& Sohn 1853;9(01):214-218

2 Hayreh SS. Pathogenesis of optic disc edema in raised intracranial pressure. Prog Retin Eye Res 2016;50:108-144

3 Carter K, Miller KM. Ophthalmology inpatient consultation. Ophthalmology 2001;108(08):1505-1511

4 Grewal DS, Chiang E, Wong E, Volpe NJ, Bryar PJ. Adult ophthalmology inpatient consults at a tertiary care teaching hospital. Ophthalmology 2014;121(07):1489-1491.e1

5 Segev-Becker A, Har-Gil M, Fainmesser P, Assia EL, Watemberg N. Yield and clinical efficacy of funduscopic examinations performed in the pediatric emergency room. Eur J Pediatr 2014; 173(03):375-379

6 Kovarik JJ, Doshi PN, Collinge JE, Plager DA. Outcome of pediatric patients referred for papilledema. J AAPOS 2015;19(04): 344-348

7 Steffen H, Eifert B, Aschoff A, Kolling GH, Völcker HE. The diagnostic value of optic disc evaluation in acute elevated intracranial pressure. Ophthalmology 1996;103(08):1229-1232

8 Ehlers JP, Shah CP, Fenton GL, Hoskins EN, Shelsta HN. Papilledema. In: Ehlers JP, Shah CP, Fenton GL, Hoskins EN, Shelsta HN, eds. The Wills Eye Manual: Office and Emergency Room Diagnosis and Treatment of Eye Disease. 5th ed. Baltimore: Lippincott Williams \& Wilkins; 2008:252-254
9 Tzekov C, Cherninkova S, Gudeva T. Neuroophthalmological symptoms in children treated for internal hydrocephalus. Pediatr Neurosurg 1991-199217(06):317-320

10 Katz DM, Trobe JD, Muraszko KM, Dauser RC. Shunt failure without ventriculomegaly proclaimed by ophthalmic findings. J Neurosurg 1994;81(05):721-725

11 Newman NJ. Bilateral visual loss and disc edema in a 15 -year-old girl. Surv Ophthalmol 1994;38(04):365-370

12 Lee HJ, Phi JH, Kim SK, Wang KC, Kim SJ. Papilledema in children with hydrocephalus: incidence and associated factors. J Neurosurg Pediatr 2017;19(06):627-631

13 Levatin P, Raskind R. Delayed appearance of papilledema. Can J Ophthalmol 1973;8(03):451-455

14 Nazir S, O’Brien M, Qureshi NH, Slape L, Green TJ, Phillips PH. Sensitivity of papilledema as a sign of shunt failure in children. J AAPOS 2009;13(01):63-66

15 Selhorst JB, Gudeman SK, Butterworth JF IV, Harbison JW, Miller JD, Becker DP. Papilledema after acute head injury. Neurosurgery 1985;16(03):357-363

16 Wilne S, Collier J, Kennedy C, Koller K, Grundy R, Walker D. Presentation of childhood CNS tumours: a systematic review and meta-analysis. Lancet Oncol 2007;8(08):685-695

17 Lewis DW, Qureshi F. Acute headache in children and adolescents presenting to the emergency department. Headache 2000;40(03): 200-203

18 Conicella E, Raucci U, Vanacore N, et al. The child with headache in a pediatric emergency department. Headache 2008;48(07):1005-1011

19 Ivan Y, Ramgopal S, Cardenas-Villa M, et al. Feasibility of the digital retinography system camera in the pediatric emergency department. Pediatr Emerg Care 2018;34(07):488-491 